\title{
EFEITO DA MASSAGEM PRÉVIA À PUNÇÃO VENOSA NA REAÇÃO DO PRÉ-ESCOLAR E ESCOLAR
}

\author{
Rosângela Martins Garcia* \\ Ana Lúcia de M. Horta** \\ Fernanda Farias***
}

\begin{abstract}
GARCIA, R. M. et al. Efeito da massagem prévia à punção venosa na reação do pré-escolar e escolar. Rev.Esc.Enf.USP, v.31, n.1, p. 119-28, abr. 1997.

Este trabalho tem por objetivo descrever o efeito da massagem efetuada pelos pais, na reação do pré-escolar e escolar hospitalizado, à punção venosa. Analisaramse as reações das crianças quanto aos parâmetros de sinais vitais, verbalização $e$ comunicação não-verbal. Os resultados obtidos mostraram que a massagem teve ação significativa nas reações não-verbais principalmente as relacionadas ao relaxamento muscular. Os efeitos sobre os sinais vitais não apresentaram alterações entre os dois procedimentos, sem massagem e com massagem, que foram realizados na mesma criança.
\end{abstract}

UNITERMOS: Alívio da dor. Massagem. Segurança emocional. Participação dos pais. Punção venosa.

\section{INTRODUÇÃO}

$\mathrm{Na}$ hospitalização do paciente pediátrico são observados períodos de estresse e insegurança que podem estar relacionados ao grau de compreensão da situação que varia conforme a faixa etária, pelo ambiente e pessoal estranhos e pelos procedimentos invasivos experienciados pelas próprias crianças ou observados em outras. Esses fatores geram reações desagradáveis nas crianças, como conseqüência da dor e da ameaça de lesão iminente.

Essas reações são descritas pelas autoras SAVASTANO et al. ${ }^{(13)}$ e WHALEY; WONG ${ }^{(15)}$ como medo, agressividade, ansiedade e fuga e variam em intensidade de acordo com a idade.

\footnotetext{
* Enfermeira. Ex-residente do IDPC. Mestranda pela EEUSP

** Doutoranda pela EEUSP. Docente da disciplina de Enfermagem Pediátrica do Departamento de Enfermagem da UNIFESP

*** Mestranda pela EEUSP. Diretora do Serviço de Enfermagem do IDPC
} 
Durante a realização de procedimentos invasivos em crianças internadas na seção de pediatria de um hospital governamental, foi possível confirmar a presença dessas reações além de verificar também um sentimento de impotência do acompanhante em ajudar a criança e a tensão dos profissionais que realizavam o procedimento.

A dor, definida por BRUNNER; SUDDARTH(3) como " uma experiência sensitiva e emocional, subjetiva e desagradável associada à lesão real ou potencial do tecido", é transmitida por terminaçōes nervosas que podem ser estimuladas por fatores mecânicos, químicos ou térmicos. Essas terminações são atingidas por estímulos com potencial para lesar os tecidos. Para que um estímulo seja transmitido dos receptores ao córtex cerebral, que então enviará como resposta a sensação de dor, é necessária a presença de fibras e substâncias que favoreçam ou impeçam a ascensão desses estímulos até o cérebro.

Como fatores que favorecem sua transmissão temos as fibras finas e a substância $\mathrm{P}$ que é um peptídeo, presente no corno dorsal da medula, e age como neurotransmissor dos impulsos transmitidos por essas fibras. As fibras grossas e a substância gelatinosa, também encontrada no corno dorsal da medula, inibem a passagem desses estímulos. Assim, a transmissão ou não do impulso doloroso dependerá do grau de estimulação das fibras finas, que a favorece, ou das fibras grossas, que a inibe. Esse processo 6 citado por BEVILAQUA et al ${ }^{(1)}$ como a teoria da comporta, descrita por Melzac e Wall. Além das estruturas e substâncias referidas que atuam inibindo a ascensão dos estímulos dolorosos, existem também as encefalinas e endorfinas que são peptídeos endógenos com ação semelhante à morfina e cuja liberação tem como efeito o alívio da dor.

$O$ aumento na liberação de endorfina e encefalina pode ser desencadeado por técnicas como as citadas por BRUNNER; SUDDARTH ${ }^{(2)}$ que são "placebo, acupuntura e estimulação elétrica transcutânea do nervo." DAVIS ${ }^{(6)}$ menciona a estimulação tátil e as emoções como fatores que podem controlar a endorfina, hormônio natural que alivia a dor.

No entanto a dor, um sintoma subjetivo que difere entre os indivíduos, necessita de parâmetros para avaliar sua manifestação. CLARO ${ }^{(5)}$ cita Abu-Saad que utilizou em seu instrumento para avaliação da dor parâmetros fisiológicos como pulso, respiração e pressão arterial, e parâmetros comportamentais como vocalização, expressão facial e movimentos corporais. PIMENTA ${ }^{(1)}$ cita: " A resposta fisiológica à dor, pela estimulação simpática, produz aumento da freqüência respiratória, da freqüência cardíaca e da pressão arterial, vasoconstrição periférica, sudorese, aumento da tensão muscular e dilatação das pupilas para dores de leve à moderada."

A partir disso acreditamos que a estimulação tátil por massagem realizada pelos pais , poderia atuar na redução da sensação de dor das crianças nos procedimentos invasivos.

A participação dos pais nos procedimentos invasivos é vista, sob a ótica da criança, como uma fonte de segurança principalmente durante a hospitalização. 
(WHALEY; WONG, ${ }^{15}$ ). No entanto os pais apresentam sentimentos de culpa, dor, terror e sofrimento pela hospitalizącão do filho, o que pode dificultar sua participação nesses procedimentos. (HORTA, ${ }^{8}$ ).

Porém a atuação dos pais pode acontecer de forma efetiva, de acordo com observação feita por PINHEIRO; LOPES ${ }^{(12)}$, quando a mãe recebe explicação sobre os procedimentos a serem realizados na criança e consegue participar dos mesmos, há uma diminuição na manifestação de ansiedade e angústia que na maioria das vezes é percebida e transmitida à criança. Acreditamos que essas manifestações atuem da mesma maneira no pai, uma vez que sua participação no tratamento dos filhos tem sido crescente.

Para tanto, embasadas na afirmação de DAVIS( ${ }^{(6)}$ de que "o contato físico transmite amor e pode desencadear alterações metabolicas e químicas no corpo, as quais auxiliam na cura.", decidimos utilizar a massagem como meio de redução nas reações das crianças aos procedimentos invasivos.

A massagem é considerada como uma forma de toque terapêutico por promover o bem-estar, como afirma BYASS ${ }^{(4)}$. No entanto MALINSKI ${ }^{(10)}$; KRIEGER $^{(9)}$; PIMENTA $^{(11)}$ e SCHOENHOFER ${ }^{(14)}$ apresentam conceitos e aspectos do toque terapêutico que discordam dessa definição.

Para KRIEGER (9) e SCHOENHOFER ${ }^{(14)}$ " $O$ toque terapêutico consiste na colocação das mãos por aproximadamente dez a quinze minutos sobre ou próximo do corpo de uma pessoa doente por alguém que tem a intenção de ajudar."

MALINSKI ${ }^{(10)}$ conceitua toque terapêutico, do ponto de vista da Teoria de Enfermagem de Rogers, como "... uma troca ou transferência de energia entre profissional e cliente."

PIMENTA $^{(11)}$ apresenta três aspectos básicos que devem ser desenvolvidos pelo profissional para a aplicação do toque terapêutico: "concentração,entrar em estado meditativo e sentir o campo energético do paciente".

Os conceitos apresentados não caracterizam o procedimento deste estudo como toque terapêutico. Sendo assim, ficou estabelecido que a técnica utilizada neste estudo seria denominada massagem.

É importante ainda destacar as características de cada faixa etária onde acredita-se que a massagem traga benefícios como relaxamento físico e redução da sensação de dor. As autoras SAVASTANO ${ }^{(13)}$ e WHALEY; WONG ${ }^{(15)}$ descrevem os pré-escolares como exibidores dos seguintes comportamentos: curiosidade, atenção bem desenvolvida, imaginação fértil e pouca noção de seus limites corporais. Esses comportamentos geram reações como negativismo, ansiedade por coisas desconhecidas e medo de experiências invasivas com solução de continuidade. Essas reações estão relacionadas ao pensamento "mágico" e causalista característico nas crianças dessa faixa etária.

Os escolares são apresentados pelas mesmas autoras como manifestantes de comportamento instável relacionado ao aumento da independência e à 
necessidade de estarem em grupos. Por essas características fazem grande esforço para serem corajosos e preocupam-se com a incapacidade e a recuperação incerta.

Apoiadas nesses conceitos, desenvolvemos o presente estudo com o objetivo de observar o efeito da massagem efetuada pelos pais, na reação do pré-escolar e escolar hospitalizados à punção venosa.

\section{METODOLOGIA}

O estudo foi realizado na seção de pediatria de um hospital da rede estadual, composta por 22 leitos, que admitia crianças de 1 mês a 12 anos.

A população foi constituída por 15 crianças sendo 6 pré-escolares e 9 escolares de ambos os sexos, internadas em alojamento conjunto, com seus respectivos pais, que após solicitação para participação se mostraram disponíveis a realizar o procedimento. Essas crianças foram submetidas à punção venosa para coleta de exames pré e pós -operatórios.

Os dados foram registrados em instrumento composto por: dados pessoais da criança, parâmetros das reações fisiologicas, parâmetros da comunicação nãoverbal e vocalização (Anexo I).

Os parâmetros observados foram: palidez, transpiração, tensão muscular, choro,apertar os dentes, cerrar os lábios, abertura ampla dos olhos, agitação, comportamento físico agressivo (chutar, bater, morder e unhar), pulso, respiração e pressão arterial. Esses parâmetros são citados por CLARO ${ }^{(0)}$ e PIMENTA ${ }^{(11)}$ como reações não-verbais e fisiológicas apresentadas pelas crianças que sentem dor. As autoras também destacam o choro como a primeira reação à dor a ser manifestada.

Antes de iniciar a coleta de dados, a pesquisadora se apresentava ao pai/ mãe e à criança, em seguida explicava os objetivos do trabalho e como ele seria desenvolvido. Após aceitação em participar do trabalho era iniciada a abordagem da criança, explicando como ela participaria do estudo.

A coleta de dados foi dividida em duas etapas. Na primeira a pesquisadora verificava os sinais vitais antes da punção venosa. Durante a mesma observava as reações verbais e não-verbais e após a punção verificava novamente os sinais vitais.

A segunda etapa envolveu a observação da criança durante a segunda punção venosa, que geralmente acontecia no 60 dia após a cirurgia. Neste procedimento eram observados os mesmos dados da primeira etapa, nas mesmas crianças, porém 15 a 30 minutos antes de iniciar a coleta de sangue, os pais aplicavam a massagem, cuja técnica é descrita a seguir, e os sinais vitais eram verificados antes da punção, com aplicação da massagem, e logo após a mesma.

A técnica da massagem aplicada neste estudo consistiu em realizar movimentos circulares utilizando a palma das mãos e as pontas dos dedos de 
ambas as mãos, com pressão moderada. Foi empregada nas regiões cervical, torácica posterior, lombar, torácica anterior, abdominal, e membros superiores sucessivamente, durante 15 minutos (massagem segundo DAVIS modificada).

Ao final da segunda etapa solicitava-se à pessoa que realizou a massagem para expor suas impressões sobre o que ela sentiu durante a aplicação da mesma e quais as diferenças de comportamento observadas por ela durante aquele procedimento e os anteriores.

A análise dos resultados foi realizada utilizando a categorização das reações dos pré-escolares e escolares segundo os parâmetros descritos por CLARO $^{(\hat{)})}$ e PIMENTA ${ }^{(1)}$.

\section{RESULTADOS E DISCUSSÃO}

Os resultados para ambas faixas etárias são apresentados na tabela a seguir.

De acordo com o que pudemos observar, os pré-escolares e escolares manifestaram redução na reação aos parâmetros de: agitação, cerrar os lábios, transpiração, apertar os dentes e palidez no procedimento realizado após a massagem.

Para os escolares as manifestações apresentaram redução para as reações de tensão muscular, apertar os dentes, cerrar os lábios, agitação, abertura ampla dos olhos, transpiração, choro e comportamento físico agressivo, no procedimento com massagem.

TABELA : Distribuição da freqüência das reações não-verbais dos pré-escolares e escolares durante a punção venosa, São Paulo, 1995.

\begin{tabular}{|c|c|c|c|c|}
\hline \multirow{3}{*}{$\begin{array}{c}\text { REAÇÃO } \\
\text { NÃA-VERBAL }\end{array}$} & \multicolumn{4}{|c|}{ FAIXA ETÁRIA } \\
\hline & \multicolumn{2}{|c|}{ PRÉ-ESCOLAR } & \multicolumn{2}{|c|}{ ESCOLAR } \\
\hline & S/massagem & C/massagem & S/massagem & $\mathrm{C} / \mathrm{massagem}$ \\
\hline PALIDEZ & 2 & 1 & 2 & 1 \\
\hline TRANSPIRAC, & 6 & 4 & 5 & 2 \\
\hline TENSÃO MUSCULAR & 6 & 4 & 9 & 2 \\
\hline CHORO & 6 & 6 & 6 & 3 \\
\hline APERTAR OS DENTES & 3 & 2 & 6 & 2 \\
\hline CERRAR OS LÁBIOS & 3 & 1 & 6 & 2 \\
\hline \multicolumn{5}{|l|}{ ABERTURA AMPLA DOS } \\
\hline OLHOS & 6 & 6 & 9 & 6 \\
\hline AGITAÇAO & 5 & 1 & 5 & 1 \\
\hline \multicolumn{5}{|l|}{ COMPORTAMENTO FÍSICO } \\
\hline AGRESSIVO & 1 & 1 & 2 & 1 \\
\hline
\end{tabular}

\footnotetext{
* A tabela acima não apresenta total porque cada criança apresentou mais de uma reação.
} 
Os resultados dos procedimentos sugeriram um efeito positivo da massagem para ambas faixas etárias.

Além dessas reações analisaram-se também as alterações de pulso, respiração e pressão arterial que foram parâmetros fisiologicos utilizados por Abu-Saad, citado por CLARO (ే) , para avaliação da manifestação de dor.

Esses parâmetros fisiológicos não apresentaram alterações significativas entre a primeira e a segunda etapas. Acreditamos que essa não variação esteja relacionada ao estresse psíquico que, segundo WHALEY; WONG ${ }^{(15)}$, para o préescolar está diretamente associado à "perda" do sangue que ele vê saindo para o tubo de coleta. No escolar o estresse surge basicamente pelo medo da lesão corporal e da "incapacitação" do membro, além do ambiente hospitalar e dos instrumentos utilizados para a verificação dos sinais vitais que atuam no estresse das duas faixas etárias aqui estudadas.

A vocalização foi outro parâmetro utilizado por Abu-Saad, citado por $\mathrm{CLARO}^{(5)}$, que apresentou os conteúdos característicos para cada faixa etária como veremos a seguir.

Para os pré-escolares a verbalização no procedimento sem massagem foi composta por gritos intensos e expressões como: "Por que eu mãe ?"; "Quero meu pai"; "Por favor mãe, não deixa. Não quero colher sangue. Dói, dói, dói."; "Pára, tá doendo." Algumas não verbalizaram e apenas choraram durante o procedimento.

No procedimento com massagem essas mesmas crianças apresentaram as seguintes expressões verbais: "Mãe fica mais perto."; "Essa agulha doeu diferente daquela da outra vez, acho que era mais fina, né tia?"; "Mãe coloca seu rosto no meu."

Os escolares se manifestaram com as seguintes frases durante a punção sem massagem: "Ai, ai, vai devagar com a agulha. Quero beber água, estou nervoso."; "Quero meu pai",( sendo agressivo com a mãe, chegando a mordê-la); "Acho que não vou agüentar"; "Faz devagar! Vai sair muito sangue igual do outro bebê?" ; "Não quero tirar sangue. Tá doendo!"; "Pára, pára eu não quero!” . Todas as verbalizações foram acompanhadas por gritos intensos.

Na punção venosa com massagem as mesmas crianças expressaram-se da seguinte forma: "Ai, ai, vai devagar." ; "Não quero colher sangue." ; "Não preciso mais chorar." ; "Não vou chorar, não tenho mais medo." Uma das crianças apenas tampou os olhos com o outro braço sem dizer nada, nem chorar.

Ambas faixas etárias apresentaram como reação comum no procedimento após a massagem, a manutenção do membro que estava sendo puncionado imóvel, o que não aconteceu no procedimento sem massagem.

Segundo Bond, citado por CLARO ${ }^{(5)}$, as crianças respondem a um estímulo doloroso com afastamento a esse estímulo. Podemos portanto supor que houve uma possível diminuição do estímulo doloroso junto com um aumento da segurança emocional conseqüente ao controle que as crianças conseguiram 
exercer sobre si mesmas, na situação do procedimento. Essas manifestações são confirmadas também na verbalização dos pais que apontaram as seguintes diferenças de comportamento apresentadas pelos filhos entre os dois procedimentos:

" ... nas outras vezes ele ficava angustiado, ansioso, perguntando a todo momento quem ia colher. No momento da coleta não deixava o braço para colher e tentava adiar a coleta. ... depois da massagem ele ficou calmo, não fez nenhuma pergunta sobre quem ia colher nem tentou fugir. Eu o senti confiante e tranqüilo. Gostei de ter aprendido essa massagem ..."

" Não dá para comparar! Das outras vezes precisava os outros pais virem segurar e a moça do laboratório não conseguia colher porque minha filha ficava nervosa e se agitava demais. Hoje ela gritou bastante mas não precisou ninguém segurá-la, nem eu."

"... normalmente ele gritava bastante e esperneava tanto que eu quase não podia segurar. Dessa vez ele chorou, olhou para onde estava colhendo o sangue mas não gritou, me pediu que chegasse mais perto e me abraçou com o braço que estava livre. Ele pareceu mais tranqüilo."

" ... acho que ela era a mais difícil de colher. Ninguém podia se aproximar dela. Hoje ela ficou relaxada, chorou um pouco mas ninguém precisou segurar e aquela suadeira e mal-estar que ela tinha enquanto colhia, hoje nem sinal. Gostei muito de ter feito a massagem."

" ... ela dormiu depois da massagem e antes da coleta. Isso nunca aconteceu. $\mathrm{Na}$ hora da coleta ela não chorou, ofereceu o braço para a coleta e ninguém precisou segurar nem o braço nem ela. Nas outras vezes não se conseguia nem fazer ela deitar na cama ... . Achei muito gostoso fazer a massagem porque além do bem-estar que ela apresentou eu também me senti muito bem enquanto fazia."

Considerando tudo que foi apresentado podemos pensar que a massagem atuou não só como uma técnica para relaxar e possivelmente reduzir a dor das crianças no procedimento, mas também permitiu uma intervenção orientada dos pais junto aos filhos, ajudando-os a enfrentarem um "momento" doloroso e invasivo para eles.

\section{CONSIDERAÇÕES FINAIS}

Podemos afirmar que a aplicação da massagem pelos pais nas crianças causou um relaxamento físico importante, aumentou a segurança emocional e permitiu um melhor controle da situação pela criança durante o procedimento invasivo, o que foi evidenciado pelos resultados apresentados pelas reações nãoverbais e pelas verbalizações dos pais e dos filhos.

Além disso a massagem orientada pareceu favorecer uma inter-relação efetiva dos pais com os filhos permitindo a troca de carinho, afeto e energia, o que resultou no aumento da confiança e segurança entre eles. 
Espera-se que através deste haja estímulo para o desenvolvimento de outros trabalhos que evidenciem com maior clareza o mecanismo dessas reações e a possível redução da dor através da massagem em situações diversas.

\section{REFERÊNCIAS BIBLIOGRÁFICAS}

1. BEVILAQUA, F. et. al. Manual de fisiopatologia clínica, $2^{2}$ ed. Sao Paulo, 1979.

2. BRUNNER, L. S. ; SUDDARTH, D. S. Prática de enfermagem, $2^{2}$ ed. , Rio de Janeiro , Interamericana, 1980, p. 138: assistência ao paciente cirúrgico.

3. BRUNNER, L. S. ; SUDDARTH, D. S. Tratado de enfermagem médico-cirúrgica, $7^{\text {a }}$ ed. , Rio de Janeiro, Guanabara-Koogan, 1992.

4. BYASS, R. Soothing Body and Soul, Nurs. Times, v. 84, n. 24, p. 39-41, 1988.

5. CLARO, M. T. Escala de faces para avaliacão da dor em criancas: etapa preliminar. Ribeirão Preto, 1993 Dissertação (mestrado), Escola de Enfermagem, Universidade de São Paulo.

6. DAVIS, P. K. O Poder do Toque $2^{2}$ ed. São Paulo, Best-Seller, 1990.

7. GLYTON, A. C. Fisiologia humana e mecanismos das doenças, $3^{2}$ ed. Rio de Janeiro, Guanabara, 1986.

8. HORTA, A. L. M. A inserção do familiar, o trabalho do enfermeiro e outras questões: o alojamento conjunto pediátrico, São Paulo, 1991.58 p. Dissertação (mestrado) Escola de Enfermagem, Universidade de São Paulo.

9. KRIEGER, D. Therapeutic Touch: The Imprimatur of Nursing, Am. J. Nurs., v. 75, n. 5, p. 784-7, 1975.

10. MALINSKI, V. M. Therapeutic Touch: The View from Rogerian Nursing Science, VISIONS, v. 1, n. 1, p.45-54, 1993.

11. PIMENTA, C. A. DE M. Alívio da dor: experiencias de enfermagem na utilização de técnicas não farmacológicas, Rev. Paul. Enf., v. 9, n. 2 , p. 73-7, 1990.

12. PINHEIRO, M. C. D. ; LOPES, G. T. A influência do brinquedo terapêutico na assistência de enfermagem à criança hospitalizada. Rev. Bras. Enf., v. 46, n. 2, p. 117-31, 1993.

13. SAVASTANO, H. ; et. al. Seu filho de 0 a 12 anos: guia para observaçáo do desenvolvimento e crescimento das crianças até 12 anos. $3^{a}$ ed. , São Paulo, Tbrasa, 1982 .

14. SCHOENHOFER, S. O. Affectional touch in critical care nursing: a descriptive study, Heart Lung, v. 18, n. 2, p.146-54, 1989.

15. WHALEY, L. F. ; WONG, D. L. Enfermagem pediátrica: elementos essenciais à intervenção efetiva, Rio de Janeiro, Guanabara-Koogan, 1989. 


\section{ANEXO I}

Instrumento para observação das crianças submetidas à massagem

I. Dados sobre a criança:
a) nome (iniciais):
b) nome do acompanhante (iniciais):
c) idade:
d) data de internação:

II. Dados a serem observados no primeiro procedimento:

a) procedimento realizado: punção venosa

b) reações fisiológicas:

- pulso (freqüência) :

- pressão arterial:

- freqüência respiratória:

- palidez:

- transpiração:

- tensão muscular:

- choro:

c) vocalização:

Antes*:
Antes*:
Antes*:
Sim ( )
Sim $(\quad)$
Sim ()
Sim ( )
presente( )

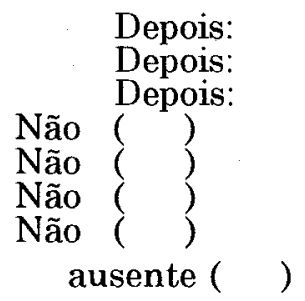

Se presente descrever o que verbaliza antes, durante e logo apos o procedimento:

d) comunicação não-verbal:

- apertar os dentes :

- cerrar os lábios :

- abertura ampla dos olhos :

- agitação :

- comportamento físico agressivo : Sim ( )

Sim ( ) Não ( )

Sim ( ) Não ( )

Sim ( ) Não ( )

Não ( )

III. Dados a serem observados no segundo procedimento:

a) procedimento realizado : punção venosa

b) reações fisiologicas:

- pulso (freqüência) :

- pressão arterial:

Antes*:

Antes*:

Depois:

- frequiência respiratória:

- palidez:

- transpiração :

- tensão muscular :

- choro :

Antes*:

Sim

Sim

Sim

Sim (

Depois:

c) vocalização:

presente ( )

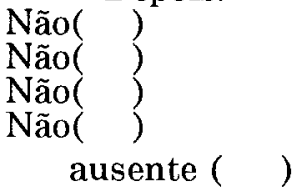

Se presente descrever o que vocalizou antes, durante e logo após o procedimento:

d) comunicação não-verbal:

- apertar os dentes :

- cerrar os lábios :

$\operatorname{Sim}(\quad)$

$\operatorname{Sim}(\quad)$

- abertura ampla dos olhos :

- agitação :

$\operatorname{Sim}()$

$\operatorname{Sim}()$

- comportamento físico agressivo : Sim (
Não ( )

Não ( )

Não ( )

Não ( )

Não ( )

* Antes da punção venosa ( após massagem no $2^{0}$ procedimento) 
GARCIA, R. M. ; FARIAS, F. ; HORTA, A. L. M. The effective of the previous massage at the reaction to venous puncture of the preschool and school. Rev.Esc.Enf.USP, v.31, n.1, p. 119-28,apr. 1997.

The objective of this work is to describe the effect of massage done by parents on the reaction to venous puncture of preschooler and school age child hospitalized. Children's reactions were evaluated through the data of vital parameters, non-verbal communication and verbalization. The results obtained indicated that massage had significant effect in non-verbal reactions, especially those related to muscular relaxation. Effects on the reaction of vital parameters showed no difference between the two procedures, with and without massage, realized on the same child.

UNITERMS: Relief of the pain. Massage. Emotional safety. Parents' participation. Venous puncture. 